\title{
Thermo-economic analysis and optimization of a vacuum multi-effect membrane distillation system
}

\author{
Chen Qian 1,*, Muhammad Burhan ${ }^{1}$, Faheem Hassan Akhtar ${ }^{1}$, Doskhan Ybyraiymkul ${ }^{1}$, Muhammad Wakil Sh \\ $\operatorname{ahzad}^{1,2}$, Li Yong ${ }^{3}$, Kim Choon $\mathrm{Ng}^{1, *}$ \\ 1. Water Desalination and Reuse Center, King Abdullah University of Science and Technology, Thuw \\ al 23955, Saudi Arabia \\ 2. Northumbria University, Newcastle upon Tyne, United Kingdom \\ 3. Institute of Refrigeration and Cryogenics, Shanghai Jiao Tong University, Shanghai, 200240, Chin
}

$a$

*Corresponding Authors, email: chen_qian@u.nus.edu; kimchoon.ng@kaust.edu.sa

\begin{abstract}
Vacuum multi-effect membrane distillation is an advanced system that possesses the features and merits of vacuum membrane distillation and multi-effect distillation. It has low operating pressure and temperature, high levels of non-volatile rejection and high energy efficiency. This study presents a thermoeconomic analysis and optimization of this novel system. A thermodynamic analysis is firstly conducted to evaluate the productivity and the energy consumption under varying design and operational conditions. Special emphases are placed on the impacts of the system configuration, including the number of effects and the overall membrane area, which are rarely covered in the literature. Results reveal that there is a tradeoff between the production rate and the energy consumption with respect to most of the operating parameters, e.g. the feed flowrate and the cooling water flowrate. An increase in the number of effects and the membrane area will reduce the energy consumption, but the specific permeate flux for the unit membrane area also becomes lower. To obtain the optimal parameters that minimize the desalination cost, an economic study is then carried out considering a wide range of thermal energy prices. It is observed that a higher feed flowrate, more numbers of effects and larger membrane areas are preferable when the energy price is higher. However, when thermal energy with low prices is available, lower feed flowrates and smaller membrane areas are recommended. The derived results will provide useful information on the vacuum multi-effect membrane distillation system for its future design and operation.
\end{abstract}

Keywords: multiple effects; vacuum membrane distillation; thermodynamic analysis; economic analysis;

\section{Introduction}

Membrane distillation (MD) has emerged as a promising process for salt water (seawater/brackish water) desalination and waste water treatment [1]. It employs hydrophobic membranes as the separation interfaces, which only allow water vapor to permeate and reject all the non-volatile solutes. The required pressure difference to drive the diffusion of water modules is created by a temperature gradient across the membrane. Compared with conventional desalination processes, e.g. MED, MSF and RO, MD possesses several key advantages, which include but are not limited to: (i) lower operational pressure and temperature, (ii) a high level of salt rejection, (iii) low sensitivity of system performance with respect to feed concentration, and (iv) high system compactness and excellent scalability [2,3]. Therefore, MD has become the subject of great research interests. 
There are four types of MD configurations [1, 4], namely, (i) direct contact membrane distillation (DCMD), where seawater and cooling water are in direct contact with the membrane, (ii) air gap membrane distillation (AGMD), which has a layer of separation gas between the membrane and the cooling water, (iii) sweep gas membrane distillation (SGMD), which uses a stream of sweep gas to carry the vapor to the condenser, and (iv) vacuum membrane distillation (VMD), which creates a vacuum condition in the permeate side and employs an external condenser condense the produced vapor. Compared with other MD configurations, VMD exhibits a higher permeate flux under the same temperature gradient due to reduced mass transfer resistance under a vacuum condition [4,5]. Additionally, sensible heat loss across the membrane is negligible, leading to higher energy efficiency $[6,7]$. Due to these promising features, VMD has gained substantial research interests. It is most competitive when renewable energy sources or low-grade waste heat are available $[8,9]$.

Similar to other thermal separation processes, VMD is energy-intensive in nature due to the high latent heat of vaporization. In order to reduce its energy consumption, several multi-stage configurations have been proposed to enable internal heat recovery. Shim et al [10] studied a multi-VMD module that recovered the waste heat from the discharge brine. The energy consumption was reported to be $2.37-2.91 \mathrm{MJ} / \mathrm{kg}$. Summers and Lienhard [11] developed a VMD system with multiple stages, which has a similar process flow with MSF. A gain-output ratio (GOR) of 4 was reported for a 20-stage system when the top temperature was $95^{\circ} \mathrm{C}$. Chung et al [12] evaluated a similar multi-stage VMD system. However, instead of assuming a fixed heat exchanger effectiveness, they considered a smaller temperature difference in the heat exchangers, which facilitated better heat recovery and resulted in higher GOR. The GOR values were reported to vary between 2.5 and 7, depending on the temperature differences in the heat exchangers and the feed salinity.

Compared with MSF, MED is more energy efficient due to more effective heat recovery [13, 14]. Therefore, it would be more promising to develop multi-stage VMD that has a similar process flow with MED. The vacuum multi-effect membrane distillation system (V-MEMD) developed by MEMSYS $[15,16]$ is such a system that combines the advantages of MED and VMD. A V-MEMD unit consists of several flat-sheet modules, which are named as effects. Similar to the MED system, the vapor generated in each V-MEMD effect is directed to the next effect to be condensed by the feed seawater, and the condensation heat is absorbed by the feed water to serve as the driving force for evaporation. The energy efficiency of the VMEMD system is similar to MED, and a GOR of 2.5-3 can be achieved using a four-effect system [15].

The general performance of the V-MEMD system with respect to different parameters are expected to be similar to that of MED and VMD. However, it is still of great impetus to investigate the V-MEMD system, not only to confirm these understandings, but also to get quantitative results and provide direct guidance for actual design and operation. Several experimental and analytical studies have been conducted to quantify the performance of the V-MEMD system. Naidu et al [17] conducted an experimental study on a MEMSYS module with only a single effect. The system was tested under different operating conditions. The permeate flux was observed to be improved by $64 \%$ when the feed temperature was increased from $310.2 \mathrm{~K}$ to $319.2 \mathrm{~K}$, while increasing the flow velocity from 1.1 to $2.2 \mathrm{~m} / \mathrm{s}$ resulted in a $14-20 \%$ improvement in permeate flux. Zhao et al [15] conducted a similar experimental study using a multi-effect configuration. The heating and cooling temperatures were observed to be the most important parameters that affect productivity and energy efficiency. The GOR was observed to be 2.5-3 for a four-effect system, which was much higher than most of the existing MD systems operating under low heat source temperatures. Muhammad et al [18] experimentally compared the single-effect module and the four-effect module with the same membrane area. The single-effect module demonstrated much higher distillate fluxes under lowtemperature heat sources, while the four-effect system was able to reduce the energy consumption by $75 \%$. Boutikos et al [19] presented a thermodynamic optimization on the V-MEMD system by investigating the 
design and operating parameters. The productivity was observed to be higher under higher feed temperatures, while the specific energy consumption can be lowered by increasing the number of effects. Additionally, the system performance can be promoted by using membranes with optimal porosity and pore size. Chen et al [20] evaluated the V-MEMD system for regenerating liquid desiccants. To obtain brines with higher concentrations, two novel configurations were proposed, which they named as two-effect steam four-effect liquid $(2 \mathrm{~S} 4 \mathrm{~L})$ and one-effect steam four-effect liquid $(1 \mathrm{~S} 4 \mathrm{~L})$. The proposed configurations were able to expand the operation range to more than $40 \mathrm{wt} \%$ under a heat source temperature of $70^{\circ} \mathrm{C}$, while the specific energy consumption was observed to be 10-50\% lower than other regenerators. Ong et al [21] integrated the V-MEMD system with a high concentration photovoltaic thermal (HCPVT) system to simultaneously produce electricity and freshwater. Low-grade waste heat $\left(75-80{ }^{\circ} \mathrm{C}\right)$ was recovered from the PV system and employed for driving the V-MEMD module. With proper thermal storage and management, the combined system was able to harvest and utilize about $85 \%$ of the solar irradiance.

The aforementioned studies provide useful information on the V-MEMD system. However, there are several key limitations with these studies. Firstly, most of them evaluated the system based on off-design conditions only and little attention has been paid to the design variables. For thermal desalination plants, the system design parameters, e.g. the number of effects and the area for heat and mass transfer, are critical for both the productivity and the energy efficiency. However, to the best of our knowledge, few studies have looked into the number of effects and the overall membrane area of the V-MEMD system, and more advanced configurations that lead to better system performance remain to be explored. Additionally, most of the existing studies attempted to optimize productivity and energy efficiency without considering the economic viability. In practical operations, the productivity and the energy efficiency usually conflict with each other, and a best trade-off between them has to be achieved by considering the final desalination cost. Moreover, higher productivity and thermal efficiencies are not always economically viable due to the added plant capital costs. Under such situations, the costs of the plant and the thermal energy should be taken into account in order to decide the optimal design and operational conditions [5]. Therefore, an economic analysis on the V-MEMD system is highly necessary. Unfortunately, economic analysis of the V-MEMD system is scarce in the literature.

The insufficient coverage of the literature on these important subjects has inspired us to fill the knowledge gaps. In this study, a systematic thermo-economic analysis will be conducted on the V-MEMD system in order to: (i) evaluate the effect of different design and operational parameters on its productivity and energy consumption, and (ii) obtain the optimal system parameters that minimize the desalination cost under varying energy prices. The novelty and originality of this study is summarized as follows: (1) quantitative performance data under different conditions will be derived for optimal design and operation of the VMEMD system; (2) key system design parameters, including the number of effects and the membrane area in each effect, will be investigated to get the best configuration that maximize the productivity and the energy efficiency; (3) an economic analysis will be conducted to get the desalination cost of the V-MEMD system under different conditions; and (4) employing the final fresh water cost as the design criteria, the optimal values of the system parameters, which usually have conflicting effects on productivity and energy consumption, will be decided under different energy prices. A thermodynamic model will be developed first and validated with experimental data. Employing the model, a parametric study will be carried out to evaluate the effects of different design and operational parameters on productivity and the specific energy consumption. Special attentions will be paid to the impacts of the system configurations, including the number of effects and the membrane area, which are rarely covered in the literature. Afterward, an economic analysis will be conducted considering a wide range of thermal energy prices, and the optimal value of each parameter will be obtained under different thermal costs. 


\section{Process description and thermodynamic modelling}

Figure 1 depicts the schematic diagram of a V-MEMD system, which consists of several production effects, a steam raiser, and an external condenser. All the components are made up of two types of frames, i.e. the membrane frame and the foil frame. The frames themselves serve as vapor channels, while the gaps between frames, which are filled with spacers, function as liquid channels.

The steam raiser is made up of several membrane frames. Hot water is supplied in the feed channel, and vapor is generated at the interface between hot water and membrane. The produced vapor permeates across the porous membrane and reaches the corresponding membrane frames. All the vapor generated in the steam raiser is then directed from the membrane frames to the first effect, which consists of alternating membrane frames and foil frames. The vapor condenses inside the foil frames. Condensation heat is released, which is transferred across the foil and then absorbed by the seawater circulated in the adjacent feed channels. Similar to the hot water, a portion of the seawater evaporates and diffuses into the adjacent membrane frames. All the vapor generated in the first effect flows to the foil frames of the second effect, while the seawater exiting the first effect enters the feed channels in the second effect. The second effect is has a lower pressure than the first effect, and the processes happened in the first effect can be induced again. In this way the condensation heat is recovered and reused, thus improving productivity and energy efficiency. Such processes are repeated in the subsequent effects that are at progressively lowered pressure conditions. Finally, vapor produced by the last effect is condensed using a cooling water stream in the external condenser. The condensate is collected at each effect and the condenser as the product. The exception is the distillate of the first effect, which will return to the hot water tank to maintain a constant water level.

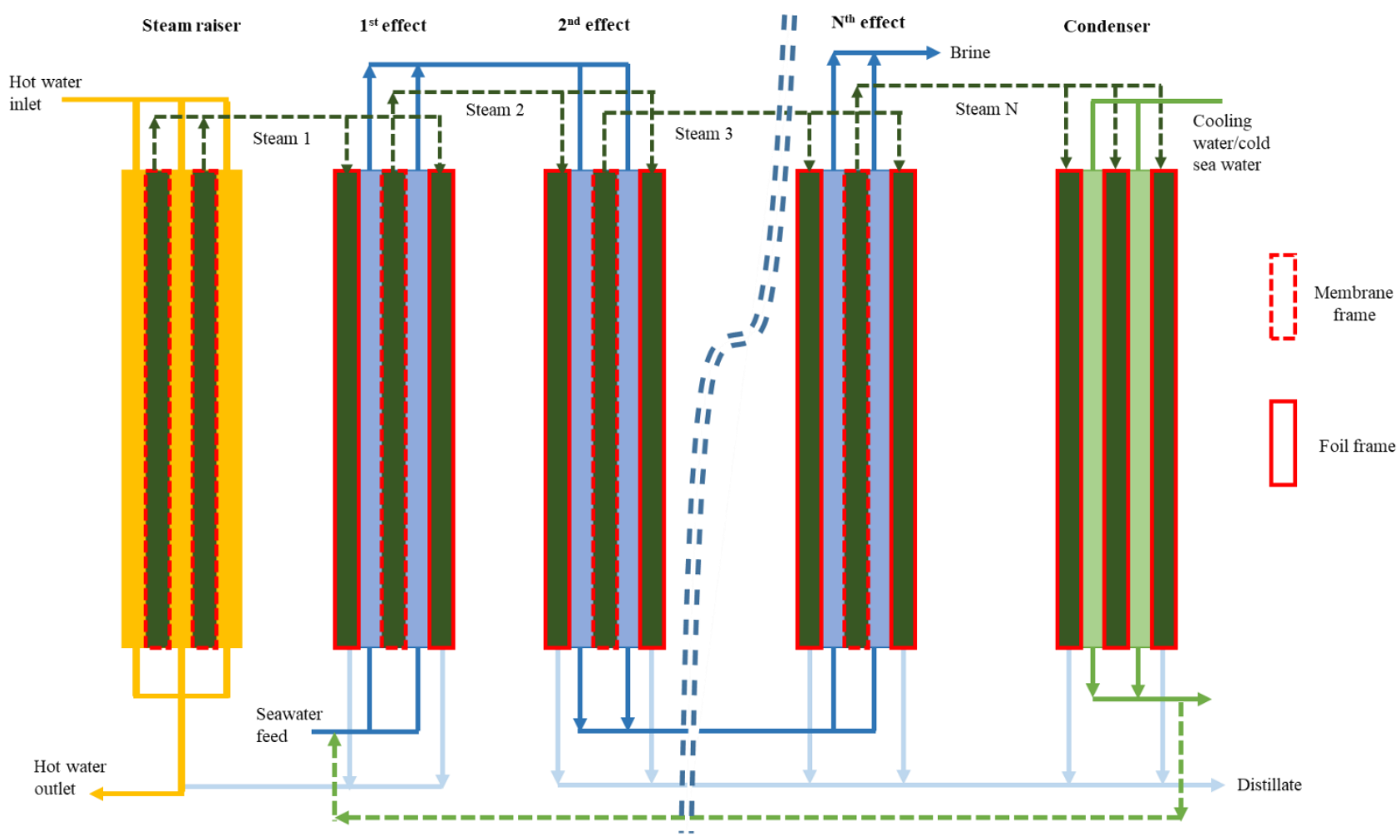


To enable a thermodynamic analysis and optimization on the V-MEMD system, a semi-empirical model is developed considering heat transfer between the fluid and the membrane and mass transfer across the membrane pores. The heat and mass transfer processes to be considered include: (a) convection heat transfer between the fluid and the frame walls, (b) mass diffusion through the membrane pores, and (c) falling film condensation in the foil frames. Figure 2 is a schematic of the processes in each component. To simplify the system model, the following assumptions and simplifications are made:

(1) The system is well adiabatic with negligible heat losses;

(2) The system is operated under steady-state conditions;

(3) The membrane is able to reject all the salts, and only water molecules are allowed to pass;

(4) The properties of water and vapor are assumed to be uniform in each effect, and they are calculated from the bulk-average pressure, temperature and salt concentration in the corresponding effects using previously derived models [22, 23].

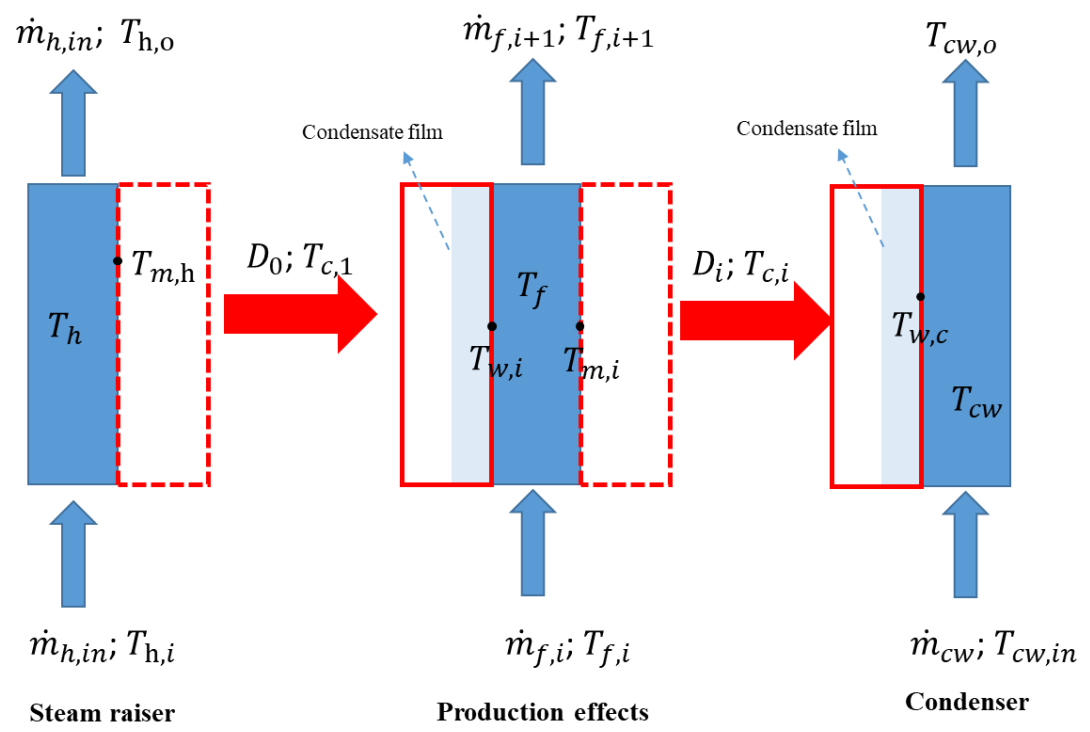

Figure 2 Schematic illustration of the heat and mass transfer processes

Table 1 summarizes the mathematical model for the V-MEMD system. The model equations have been well established in our previous publication [20]. Therefore, only the general structure and key equations are provided here for the sake of completeness. These equations will be solved using the successive iteration method. An initial guess of the steam production rate in the steam raiser will be provided first. Based on the guessed value, the membrane temperature in the steam raiser can be calculated using Eqs.2-4. Then feed temperature, plastic foil temperature, membrane temperature and vapor temperature in each effect will be obtained sequentially using Eqs.5-12. Afterwards the cooling water temperature is computed independently from Eq.13 and Eq.15. The initial guess of steam production rate is adjusted until the two cooling water outlet temperatures are identical. Employing this steam production rate, the temperatures and productivity in each component are computed, which will represent the actual system performance. Finally the overall production rate and energy efficiency, as given in Eqs.19-21, will be calculated. The readers are referred to the literature for more details about the mathematical model and the solution algorithm.

Table 1 Thermodynamic model of the V-MEMD system

\begin{tabular}{|l|l|l|l|}
\hline Component & Equation & No. & Comments \\
\hline Steam raiser & $\quad \dot{m}_{h, \text { in }}=\dot{m}_{h, o}+D_{0}$ & $(1)$ & Mass balance of hot water; \\
\hline
\end{tabular}




\begin{tabular}{|c|c|c|c|}
\hline & $\dot{m}_{h, \text { in }} H_{h, i n}=\dot{m}_{h, o} H_{h, o}+D_{0} H_{g}$ & $(2)$ & Energy balance in steam raiser; \\
\hline & $D_{0} H_{f g}=h_{m e m, h} A_{h}\left(T_{h}-T_{m, h}\right)$ & (3) & $\begin{array}{l}\text { Heat transfer from hot water to } \\
\text { membrane surface; }\end{array}$ \\
\hline & $D_{0}=C_{h} A_{h}\left[p_{s a t}\left(T_{m, h}\right)-p_{s a t}\left(T_{c 0}\right)\right]$ & (4) & $\begin{array}{l}\text { Mass transfer across the } \\
\text { membrane; }\end{array}$ \\
\hline \multirow{8}{*}{$\begin{array}{l}\text { Production } \\
\text { effects }\end{array}$} & $\dot{m}_{f, i}=\dot{m}_{f, i-1}+D_{i}$ & $(5)$ & Mass balance of seawater; \\
\hline & $\dot{m}_{f, i-1} H_{f, i-1}=\dot{m}_{f, i} H_{f, i}+D_{i} H_{g}$ & $(6)$ & Energy balance in each effect; \\
\hline & $D_{i-1} H_{f g}=\frac{k_{f i l m}}{\delta_{f i l m, i}} A_{e f f}\left(T_{c, i-1}-T_{w, i}\right)$ & (7) & $\begin{array}{l}\text { Heat transfer across condensate } \\
\text { film to foil frame; }\end{array}$ \\
\hline & $\begin{array}{l}h_{e f f, i} A_{e f f}\left(T_{w, i}-T_{f, a v e}\right) \\
\quad=\dot{m}_{f, i-1} c_{p, i}\left(T_{f, i}-T_{f, i-1}\right) \\
+D_{i} H_{f g}\end{array}$ & (8) & $\begin{array}{l}\text { Heat transfer from foil frame to } \\
\text { seawater; }\end{array}$ \\
\hline & $\delta_{\text {film }, i}=\frac{3}{4}\left[\frac{3 \mu_{w} H_{\text {foil }} D_{i-1}}{A_{e f f} g \rho_{l}\left(\rho_{l}-\rho_{v}\right)}\right]^{1 / 3}$ & (9) & $\begin{array}{l}\text { Thickness of the condensate } \\
\text { film; }\end{array}$ \\
\hline & $D_{i}=C_{h} A_{e f f}\left[p_{s a t}\left(T_{m, i}, X_{m, i}\right)-p_{s a t}\left(T_{c, i}\right)\right]$ & (10) & $\begin{array}{l}\text { Mass transfer across the } \\
\text { membrane; }\end{array}$ \\
\hline & $X_{m, i}=X_{i} \exp \left(\frac{D_{i}}{A_{e f f} \rho h_{m}}\right)$ & (11) & Concentration polarization [24]; \\
\hline & $\dot{m}_{f, i} X_{i}=\dot{m}_{f, i-1} X_{i-1}$ & (12) & Salt balance in each effect; \\
\hline \multirow[t]{3}{*}{ Condenser } & $D_{N} H_{f g}=\dot{m}_{c w} c_{p, c w}\left(T_{c w, o}-T_{c w, i n}\right)$ & (13) & $\begin{array}{l}\text { Energy balance in the } \\
\text { condenser; }\end{array}$ \\
\hline & $D_{N} H_{f g}=\frac{k_{f i l m}}{\delta_{f i l m, c}} A_{c}\left(T_{c, N}-T_{w, c}\right)$ & (14) & $\begin{array}{l}\text { Heat transfer across condensate } \\
\text { film to foil frame; }\end{array}$ \\
\hline & $\frac{k_{\text {film }}}{\delta_{\text {film }, c}} A_{c}\left(T_{c, N}-T_{w, c}\right)=h_{c} A_{c}\left(T_{w, c}-T_{c, \text { ave }}\right)$ & (15) & $\begin{array}{l}\text { Heat transfer from foil frame to } \\
\text { cooling water; }\end{array}$ \\
\hline \multirow{3}{*}{$\begin{array}{l}\text { Heat and } \\
\text { mass transfer } \\
\text { coefficients }\end{array}$} & $N u=\frac{h d}{k}=0.664 k_{d c} \operatorname{Re}^{0.5} \operatorname{Pr}^{0.33}\left(\frac{d_{h, s}}{l_{m}}\right)^{0.5}$ & (16) & $\begin{array}{l}\text { Heat transfer coefficient [ } 25, \\
26]\end{array}$ \\
\hline & $S h=\frac{h_{m} d}{D_{12}}=0.664 k_{d c} R e^{0.5} S c^{0.33}\left(\frac{d_{h, s}}{l_{m}}\right)^{0.5}$ & (17) & Mass transfer coefficient; \\
\hline & $C=\frac{2}{3} \frac{\varepsilon r_{p}}{\tau \delta_{m}}\left(\frac{8 M}{\pi R T}\right)^{0.5}$ & (18) & Mass transfer coefficient [27]; \\
\hline \multirow[t]{3}{*}{$\begin{array}{l}\text { Performance } \\
\text { indicators }\end{array}$} & $D=\sum_{i=2}^{N} D_{i}$ & (19) & Overall production rate; \\
\hline & $s D=\frac{D}{A_{m e m}}$ & (20) & $\begin{array}{l}\text { Specific flux for unit membrane } \\
\text { area; }\end{array}$ \\
\hline & $S E C=\frac{Q_{h}}{D}=\frac{\dot{m}_{h, i n} H_{h, i n}-\dot{m}_{h, o} H_{h, o}}{D}$ & (21) & $\begin{array}{l}\text { Specific energy consumption for } \\
\text { distillation; }\end{array}$ \\
\hline
\end{tabular}

\section{Model validation with experimental data}

The mathematical model is firstly validated with experimental data achieved from a four-effect MEMSYS V-MEMD module, as shown in Figure 3. In the MEMSYS module, each effect comprises of 11 frames (5 membrane frames +6 foil frames), while both the steam raiser and the condenser have 17 frames. Each frame consists of two membrane/plastic foils with a dimension of $0.33 \mathrm{~m} \times 0.48 \mathrm{~m}$. Flat-sheet polytetrafluoroethylene (PTFE) membranes with a thickness of $0.12-0.2 \mathrm{~mm}$ are employed in the module. The membrane porosity is $70-75 \%$, and the mean pore radius is around $0.2 \mu \mathrm{m}$. Inline sensors are installed to measure and record the temperatures and pressures of the water and vapor, while the distillate is collected and weighed to get the productivity. 


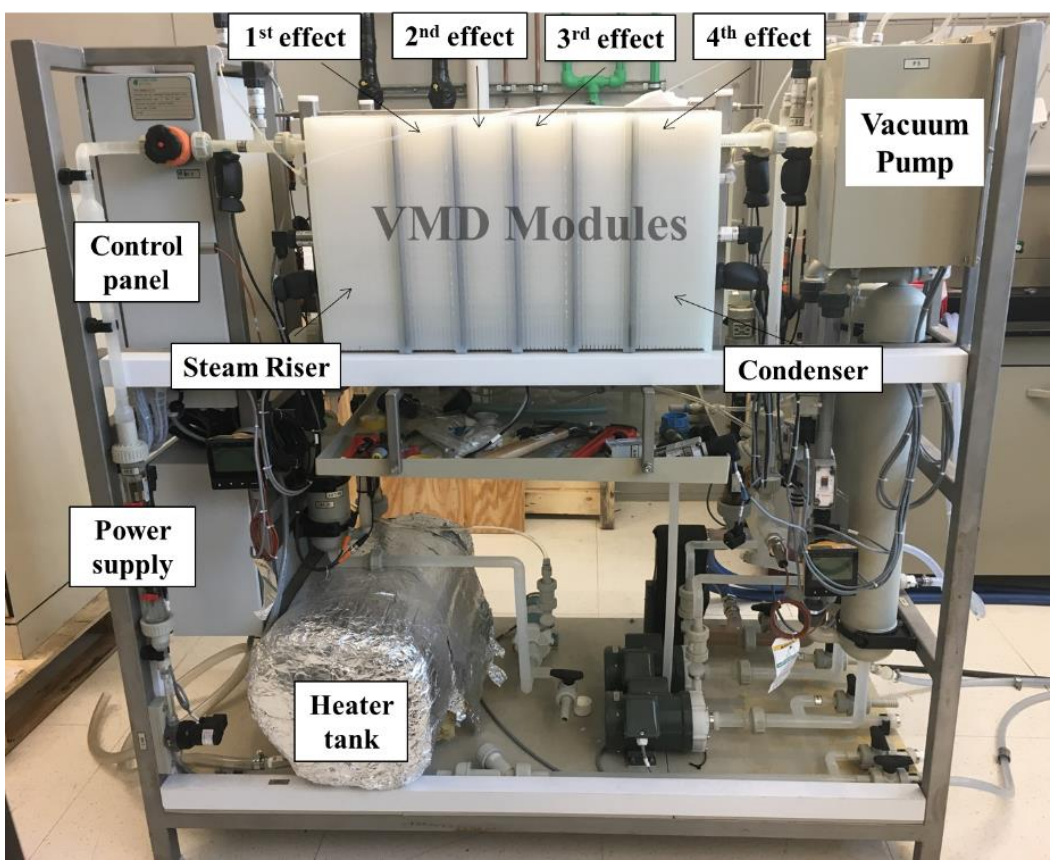

Figure 3 Pictorial view of the V-MEMD module

Experimental tests were conducted for assorted hot water temperatures, as summarized in Table 2. For each test, the temperatures and flowrates of different fluid streams are recorded and employed as the input of the mathematical model. Then water and vapor temperatures at the exits of each component as well as the distillation productivity are computed and compared with experimental measurements to validate the developed model. Figure 4(a) shows the comparison of water (hot/cooling water) and vapor temperatures between experiment and simulation under a typical operational condition. The calculated water temperatures agree perfectly with the measured values in the steam raiser and the condenser. The vapor temperatures predicted by the model also adhere to the measured value for all the effects. Figure 4(b) compares the distillate productivity, the hot water outlet temperatures and the cooling water outlet temperatures when the hot water is supplied at $25-48{ }^{\circ} \mathrm{C}$. No substantial difference is found between the experiment and the simulation results. Therefore, the model is believed to have excellent prediction capability.

Table 2 Parameters for experimental design

\begin{tabular}{|c|c|}
\hline Parameter & Value \\
\hline Hot water flowrate & $31 \mathrm{LPM}$ \\
\hline Hot water temperature & $25-60{ }^{\circ} \mathrm{C}$ \\
\hline Feed seawater flowrate & $0.75-1.25 \mathrm{LPM}$ \\
\hline Feed salinity & $35 \mathrm{~g} / \mathrm{kg}$ \\
\hline Seawater temperature & $16-20^{\circ} \mathrm{C}$ \\
\hline Cooling water flowrate & $25 \mathrm{LPM}$ \\
\hline Cooling water temperature & $16-20{ }^{\circ} \mathrm{C}$ \\
\hline
\end{tabular}




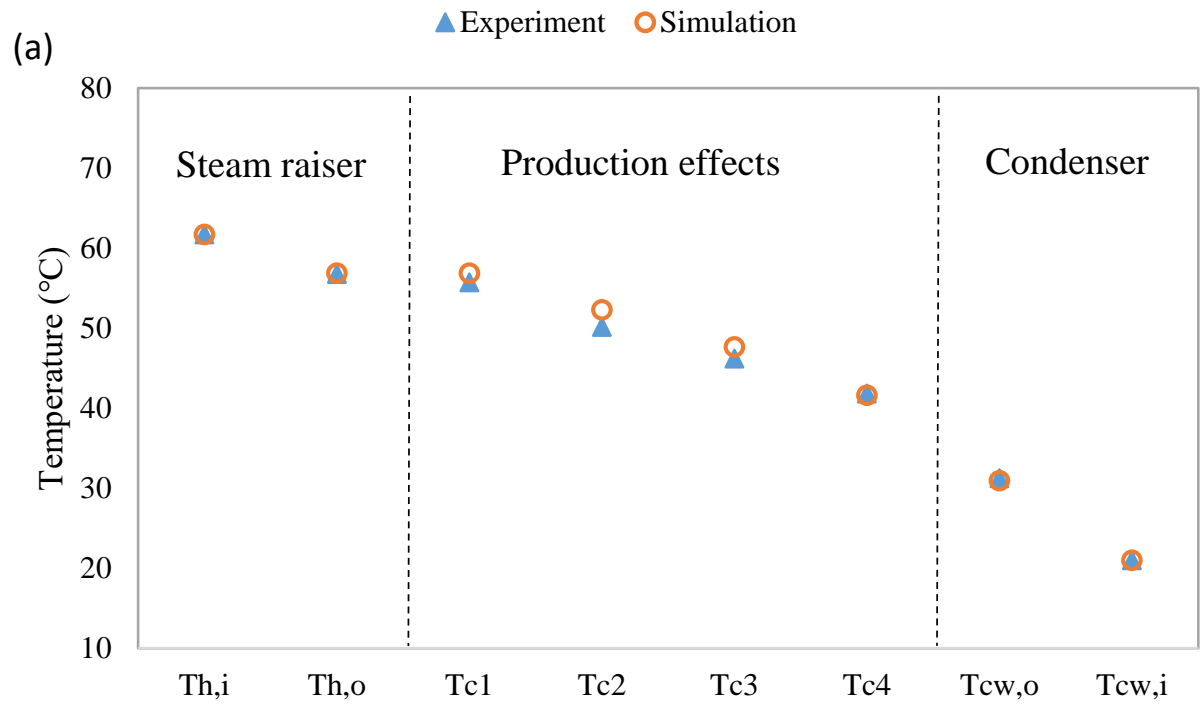

(b)
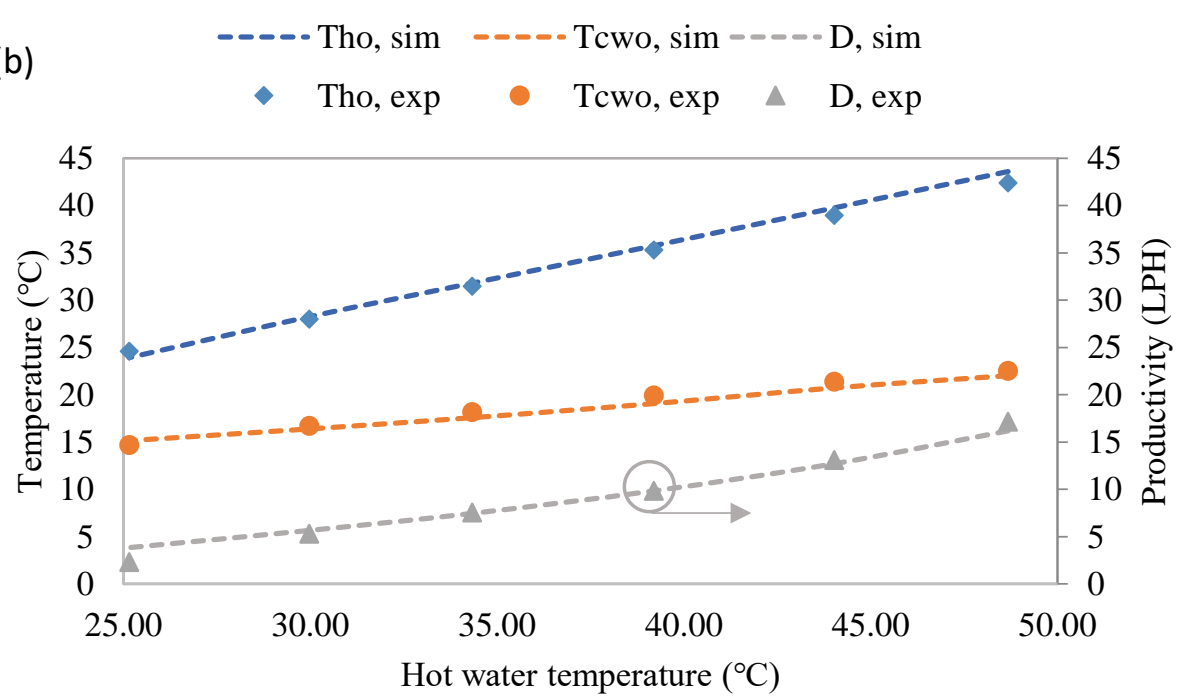

3 Figure 4 Model validation with experimental data: (a) comparison of the water and vapor temperatures

4 for typical operating conditions; $(b)$ comparison of productivity and hot/cooling water outlet

5 temperatures under different hot water inlet temperatures under a feed flowrate of 1.25 LPM, a cooling

$6 \quad$ water flowrate of 25 LPM and a cooling water temperature of $14{ }^{\circ} \mathrm{C}$

\section{Thermodynamic analysis}

9 After the validity of the mathematical model is demonstrated, it is employed to conduct a thermodynamic 10 analysis on the V-MEMD system. Different from the experimental setup which has separate cooling water supply, seawater will be employed as the cooling media and its temperature is assumed to be the same as the ambient. After exiting the condenser, a portion of the pre-heated seawater will be directed into the effects as the feed. In this way, the condensation heat from the condenser can be partially recovered. 
1 The ultimate target of the thermodynamic analysis is to minimize the desalination cost, which includes the 2 initial cost and the operational cost. Both costs are impacted by two key parameters, i.e. membrane area 3 and energy consumption. In order to reduce the cost, it is critical to increase the productivity under unit 4 membrane area and reduce the energy consumption. Therefore, the distillate productivity (or specific 5 permeate flux calculated by Eq.20) and the specific energy consumption will be adopted as the performance 6 indicators in the following analyses.

$7 \quad$ Figure 5 presents the effects of hot water and ambient temperatures on the production rate and the specific 8 energy consumption. It can be expected that the production rate increases with the hot water temperature 9 while decreases with the ambient temperature, as shown in Figure 5(a). This is because a higher temperature 10 difference between the heating and the cooling fluids will provide more heat source for evaporation. On the 11 other hand, the energy consumption for desalination will be reduced at higher hot water temperatures, as 12 revealed in Figure 5(b). With a higher hot water temperature, temperature differences across the membrane 13 will also be higher, which promotes the production and facilitates better heat recovery. It is also noteworthy 14 from Figure 5(b) that the specific energy consumption is higher at lower ambient temperatures. The reason 15 is that the feed water has to be pre-heated to the boiling temperature in the first effect, and a lower ambient 16 temperature will result in more heating energy consumption.

17 Although the temperatures of the heating and cooling streams have significant impacts, they are usually 18 subjected to external conditions, e.g. ambient conditions and availability of the heating sources. In addition, 19 the seawater temperature is usually limited to below $70^{\circ} \mathrm{C}$ in order to reduce the potential of membrane 20 scaling and fouling $[13,14]$. Therefore, a hot water temperature of $70{ }^{\circ} \mathrm{C}$ and an ambient temperature of $2125{ }^{\circ} \mathrm{C}$ will be employed in the following simulations. 
(a) $\longrightarrow \mathrm{Tamb}=20^{\circ} \mathrm{C} \longrightarrow \mathrm{Tamb}=25^{\circ} \mathrm{C} \longrightarrow \mathrm{Tamb}=30^{\circ} \mathrm{C}$
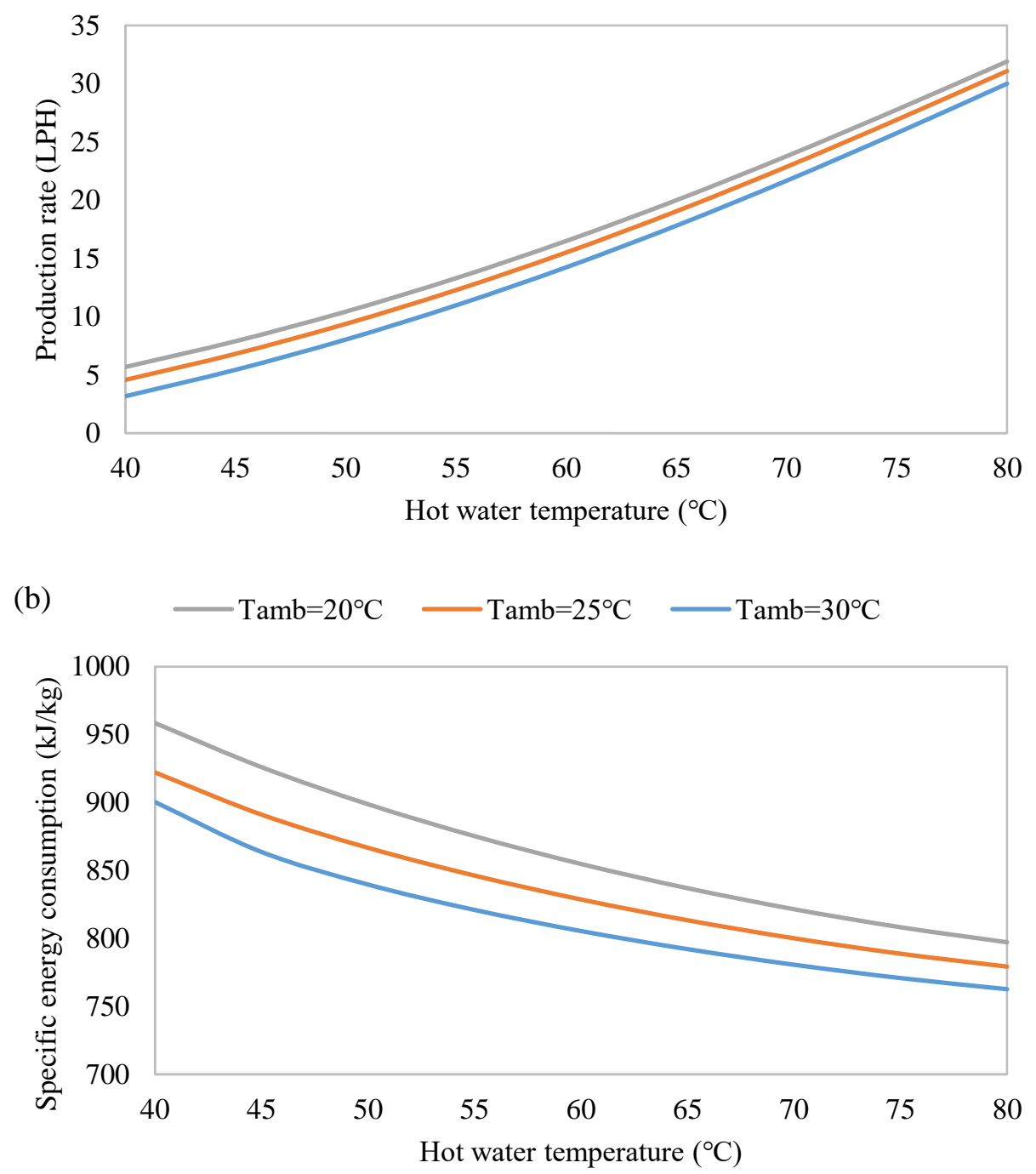

Figure 5 Effect of the fluid temperatures on (a) overall system productivity and (b) specific energy consumption under a feed flowrate of 0.75 LPM and a cooling water flowrate of 25 LPM,

Figure 6 shows the productivity and energy efficiency under different cooling water flowrates. It is clear from the figure that a higher cooling water flowrate will lead to a higher production rate due to promoted condensation. The result is consistent with the experimental observations reported in the literature [15]. Meanwhile, specific energy consumption is also increased upon increasing the cooling water flowrate. When the cooling water flowrate is higher, the feed seawater (which is separated from the cooling water) has a lower temperature when entering the first effect. Consequently, the energy consumption for seawater heating becomes higher, leading to a higher specific energy consumption for desalination. However, these effects are not significant over a wide range of flowrate. When the cooling water flowrate is increased from 15 to $50 \mathrm{LPM}$, the improvement of productivity is less than $5 \%$, while the change of specific energy consumption is marginal at $2 \%$. Therefore, the cooling water flowrate is not a key parameter for the final desalination cost. In actual operation, a lower cooling water can be adopted to reserve pumping power. 


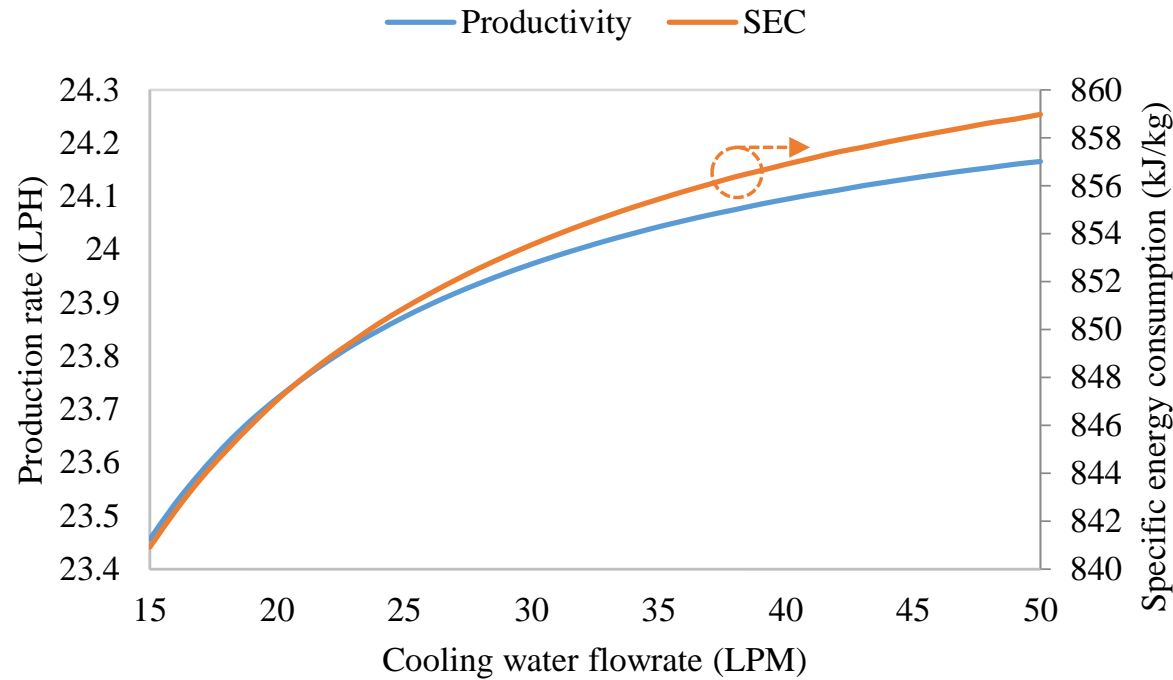

1

Figure 6 Thermal performance of the system under different cooling water flowrates under a feed flowrate of 0.75 LPM a cooling water temperature of $25^{\circ} \mathrm{C}$

Figure 7 depicts the system performance under different feed water flowrates. Similar to the effect of the cooling water flowrate, a higher feed flowrate results in not only higher productivity but also higher specific energy consumption. However, the impact of the feed flowrate is more pronounced than that of the cooling water flowrate, and its value requires special attention during practical operation. The same observations have also been reported by Naidu et al [17]. The higher productivity can be explained by promoted heat and mass transfer under a more turbulent flow, while the increase of the specific energy consumption is due to additional heating requirements for the feed seawater in the first effect. As a result, the optimal feed flowrate that minimizes the desalination cost will be the result of the best trade-off between higher productivity and higher energy consumption.

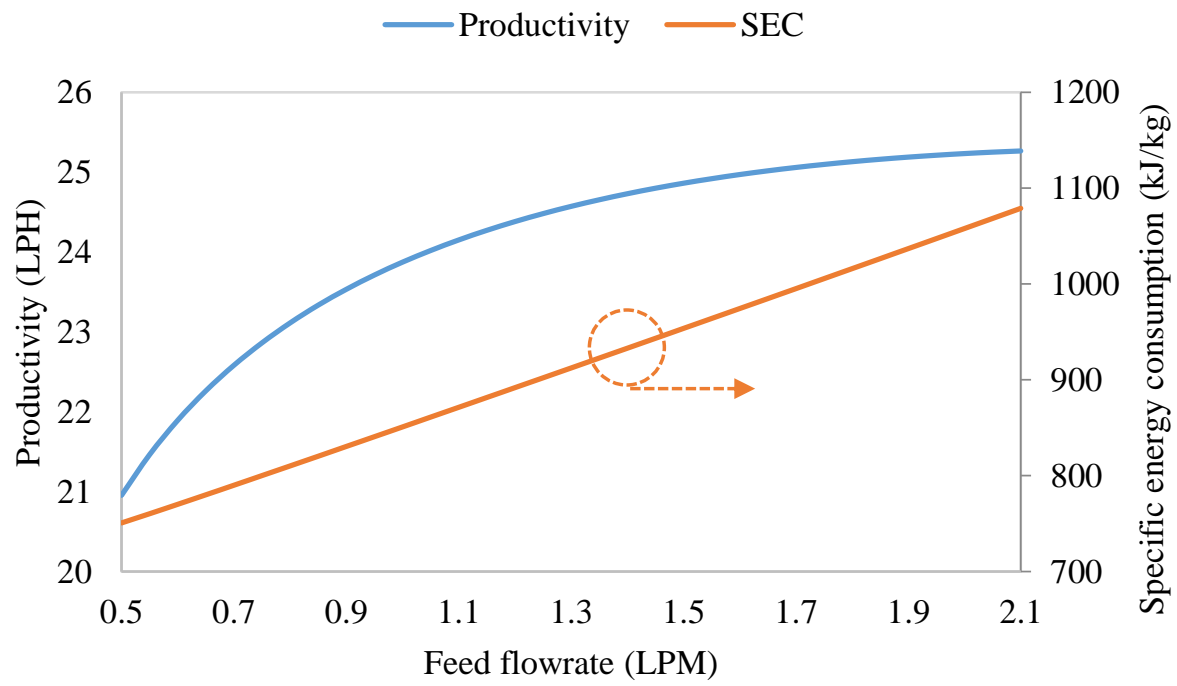


The above analyses are based on a fixed system configuration, i.e. four-effect system with 11 frames (5 membrane frames +6 foil frames) in each effect. To achieve the optimal configuration, the system is explored under different numbers of effects and membrane frames. The results are plotted in Figure 8. The total number of membrane frames presented in the figures is the sum of the membrane frames in each effect. For example, with a total number of 40 frames, a two-effect system has 20 frames in each effect, while a four-effect system has only 10 frames in each effect. As can be seen from Figure 8(a) and (b), when the system has more numbers of frames, both the production rate and the energy efficiency can be significantly improved due to more heat and mass transfer areas available. However, the specific permeate flux for the unit membrane area gets smaller, as shown in Figure 8(c), indicating that more membrane area is needed to produce the same amount of freshwater. Therefore, the economic viability of increasing the membrane area will be subjected to the relative costs of the membrane and thermal energy.

12 It is also worth to note from Figure 8(b) that the specific energy consumption can be reduced by increasing 13 the number of operating effects. However, when it comes to productivity, the dominating configuration varies for different numbers of frames. When the system has less than 16 membrane frames, the singleeffect configuration has the maximum productivity. But when the number of membrane frames ranges from 16 to 92, the two-effect configuration dominates over the other two. The four-effect configuration has the highest productivity when the total number of membrane frames exceeds 92 . In practical situations, the optimal configuration has to be determined by considering the relative costs of thermal energy and membrane.

(a) Single-effect $\longrightarrow$ Two-effect $\longrightarrow$ Four-effect

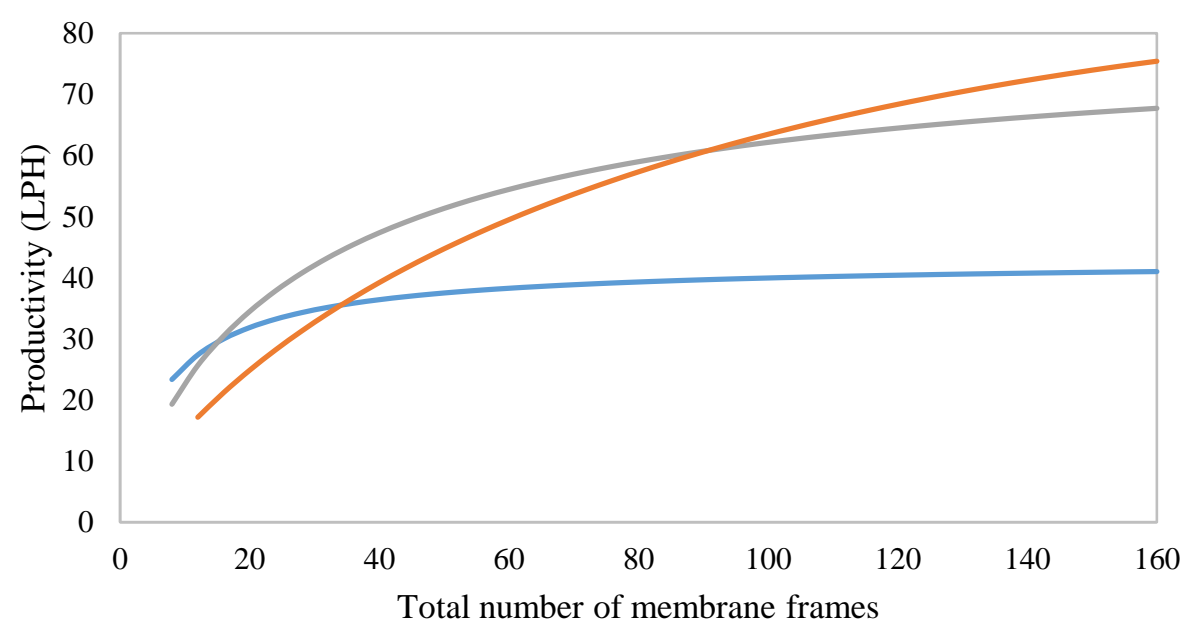


(b)

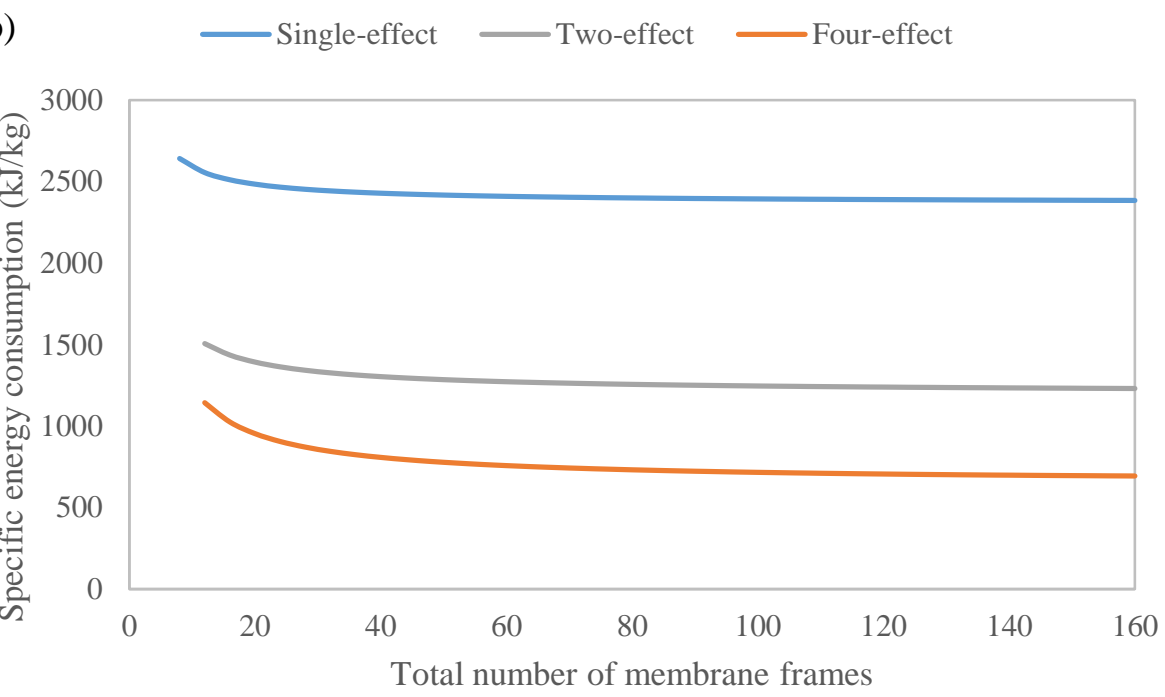

(c)
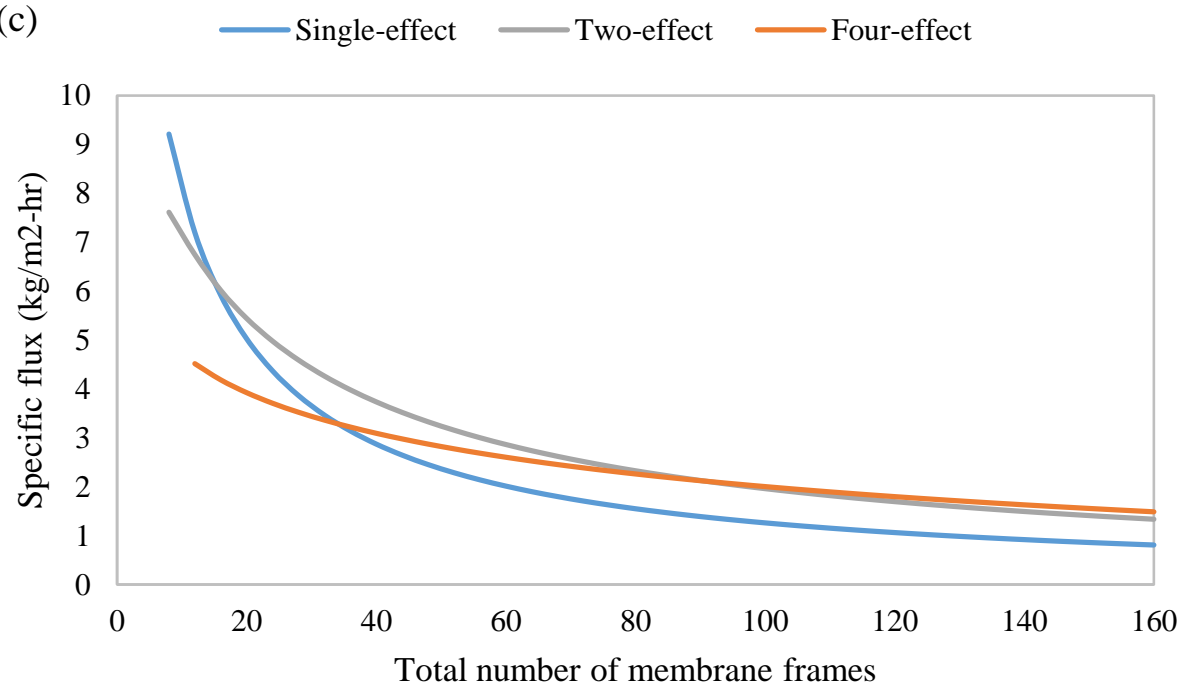

2

3 Figure 8 Effect of system configuration on (a) overall productivity, (b) specific energy consumption, and (c) specific flux for unit membrane area with a feed flowrate of 1.5 LPM, a cooling water flowrate of 25

$L P M$, a hot water temperature of $70^{\circ} \mathrm{C}$ and a cooling water temperature of $25^{\circ} \mathrm{C}$

\section{Economic analysis}

As revealed by the previous thermodynamic analyses, there is a trade-off between productivity and energy efficiency with respect to most of the design and operational parameters. Consequently, the optimal values of these parameters will be determined by the relative costs of different sources. The optimal system configuration, including the number of effects and the overall membrane area, is also subjected to the tradeoff between membrane price and energy price.

13 In order to determine the optimal values for the design and operational parameters, an economic analysis will be conducted in this section. The total cost for desalination consists of initial capital costs (direct and 
indirect) and annual maintenance and operational costs. Without loss of generality, the economic model is developed for a V-MEMD plant with a capacity of $100 \mathrm{~m}^{3} /$ day, a seawater salinity of $35 \mathrm{~g} / \mathrm{kg}$, a feed temperature of $25^{\circ} \mathrm{C}$ and a heat source temperature of $70^{\circ} \mathrm{C}$. Table 3 summarizes the data and assumptions employed in the economic model, which are acquired from peer-reviewed literatures and equipment manufacturers. It should be noted that the capacity value of $\mathrm{m}^{3} /$ day in the table is the feed seawater flowrate instead of the production rate [28]. Another important point to be noted is that the economic data are sensitive to the site where the plant is constructed and operated. Therefore, the analysis should be adapted to the local conditions in order to get the optimal values for a specific plant at a specific site.

Table 3 Summary of data and assumptions for the economic model

\begin{tabular}{|l|l|}
\hline Initial cost & \\
\hline Site development [29] & $\$ 26.42 /\left(\mathrm{m}^{3} /\right.$ day $)$ \\
\hline Pretreatment [30] & $\$ 79.25 /\left(\mathrm{m}^{3} /\right.$ day $)$ \\
\hline Membrane [28] & $\$ 60 / \mathrm{m}^{2}$ \\
\hline Membrane module [28] & $\$ 103 /\left(\mathrm{m}^{3} /\right.$ day $)$ \\
\hline Storage tank [29] & $\$ 21.14 / \mathrm{m}^{3}$ \\
\hline Utility cost [29] & $\$ 42.27\left(\mathrm{~m}^{3} /\right.$ day $)$ \\
\hline Shipping and installation [28] & $\$ 44.9\left(\mathrm{~m}^{3} /\right.$ day $)$ \\
\hline Engineering cost [28] & $\$ 44.9\left(\mathrm{~m}^{3} /\right.$ day $)$ \\
\hline Plant availability & $90 \%$ \\
\hline Plant life & 30 years \\
\hline Interest rate & $2 \%$ \\
\hline O\&M cost & \\
\hline Thermal energy cost [31] & $\$ 0-0.012 / \mathrm{kWh}$ \\
\hline Electricity cost [32] & $\$ 0.069 / \mathrm{kWh}$ \\
\hline Filtration [28] & $\$ 0.0132 / \mathrm{m}^{3}$ \\
\hline Brine disposal [28] & $0.0015 / \mathrm{m}^{3}$ \\
\hline Chemical cost [33] & $\$ 0.018 / \mathrm{m}^{3}$ \\
\hline Spares cost [28] & $\$ 0.033 / \mathrm{m}^{3}$ \\
\hline Labor cost [32] & $\$ 0.03 / \mathrm{m}^{3}$ \\
\hline Membrane replacement & $20 \% / \mathrm{year}$ \\
\hline & \\
\hline
\end{tabular}

Figure 9 shows the breakdown of desalination costs. It is obvious that energy cost and membrane cost (including initial membrane cost and annual membrane replacement cost) account for more than $80 \%$ of the overall desalination cost under most of the situations. However, the values are subjected to the change of the thermal energy price. When free thermal energy, e.g. industrial waste heat, is available, $80 \%$ of the cost comes from the membrane. But under a higher thermal energy price, the contribution of energy cost gets higher, and it approaches $70 \%$ when the thermal price is $\$ 0.012 / \mathrm{kWh}$. Due to such a significant variation of cost sources, the optimal parameters are expected to be different when the energy price is varied. 


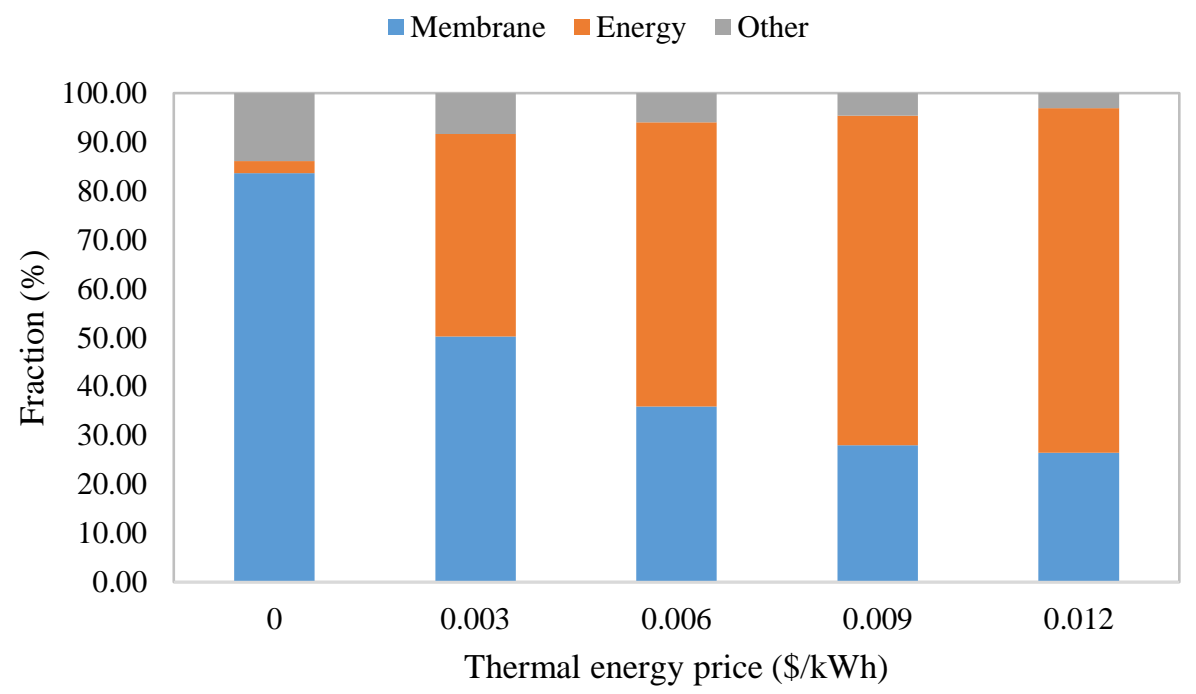

1

$2 \quad$ Figure 9 Breakdown of desalination cost under different thermal energy costs with a feed flowrate of 1.5

$3 \quad L P M$, a cooling water flowrate of $25 L P M$, a hot water temperature of $70^{\circ} \mathrm{C}$ and a cooling water temperature of $25^{\circ} \mathrm{C}$

5 Figure 10 shows the desalination costs under different feed flowrates. As revealed previously, a higher feed 6 flowrate promotes productivity while leads to a lower energy efficiency. As a result, a lower feed flowrate 7 that reduces energy consumption is preferable when the thermal price is higher, while the optimal value 8 will be higher when thermal energy is cheaper. Such a conclusion can be clearly seen from Figure 10. When 9 the steam price is higher than $\$ 0.003 / \mathrm{kWh}$, the desalination cost increases with the increase of feed flowrate. 10 However, when the thermal price is lower, the lowest desalination cost occurs at a feed flowrate of 0.7 LPM.

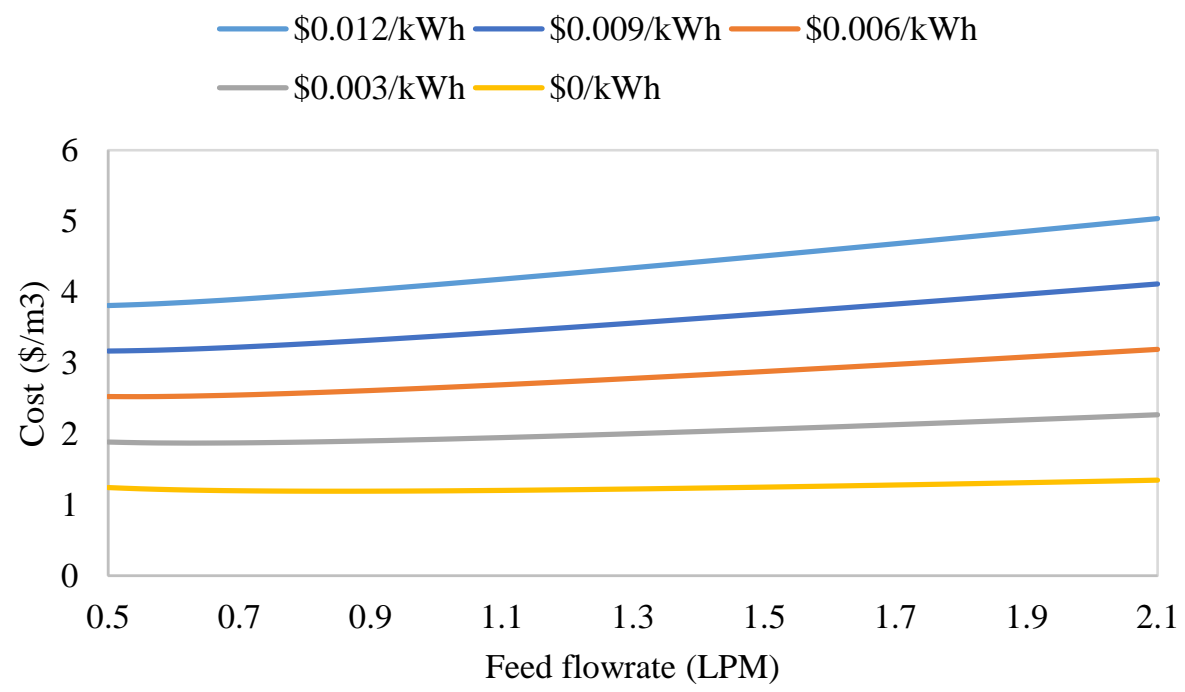

11

Figure 10 Desalination cost under different feed flowrates with a cooling water flowrate of 25 LPM, a hot 13 water temperature of $70^{\circ} \mathrm{C}$ and a cooling water temperature of $25^{\circ} \mathrm{C}$ 
1 The cooling water also impacts both productivity and energy efficiency, but the effect is very marginal.

2 Consequently, the desalination cost remains almost constant under different cooling water flowrates, as 3 illustrated in Figure 11.

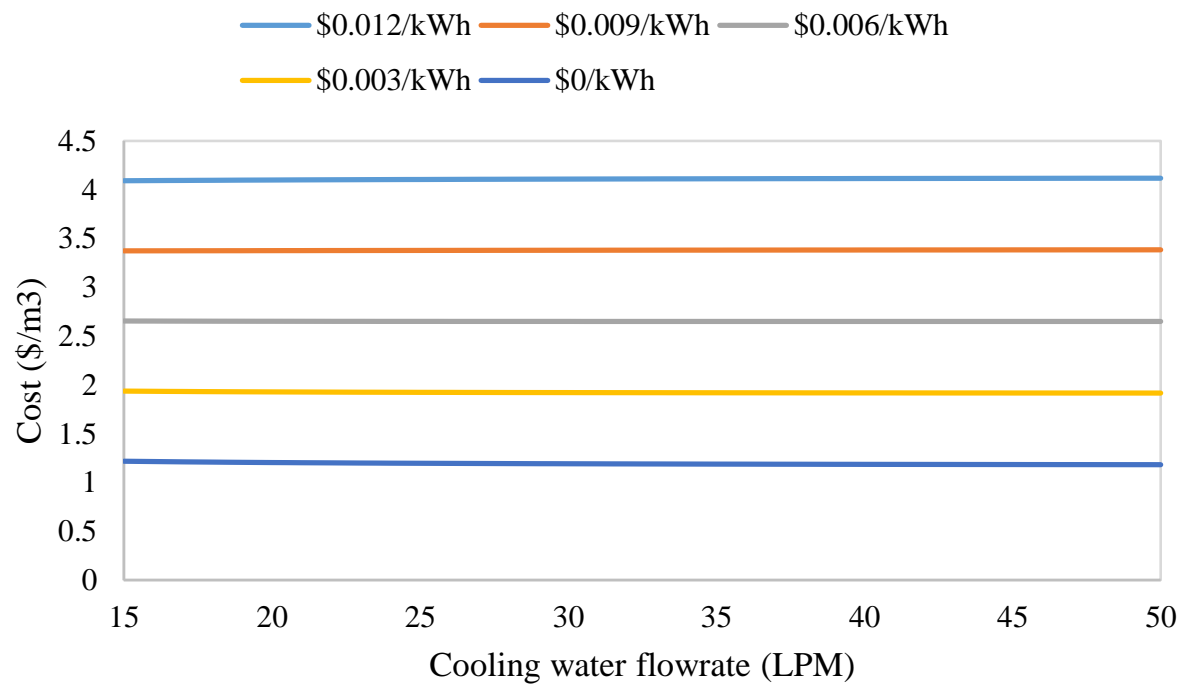

4

Figure 11 Desalination cost under different cooling water flowrates with a feed flowrate of 1.5 LPM, a hot water temperature of $70^{\circ} \mathrm{C}$ and a cooling water temperature of $25^{\circ} \mathrm{C}$

Figure 12 shows the effect of system configuration on desalination costs. The cost firstly increases when increasing the number of frames due to an improvement in productivity and a reduction of thermal energy consumption. After the number of frames exceeds a certain value, the trend will be reversed. Figure 12(a) shows the final cost when the thermal price is high at $\$ 0.012 / \mathrm{kWh}$. The optimal numbers of membrane frames are 32, 60 and 92 for single-effect, two-effect and four-effect configurations, respectively. Due to the dominating role of energy cost under a high thermal energy price, the four-effect configuration is more cost-effective than the other two configurations. However, a different situation is observed when heat sources with lower prices are available, as shown in Figure 12(b). The optimal numbers of membrane frames become smaller (16, 32 and 56 for single-effect, two-effect and four-effect configurations, respectively). This is because the effect of reducing energy consumption cannot be justified by a higher membrane cost when thermal energy is cheap. Also, the two-effect configuration yields the lowest water cost because of its highest productivity. 


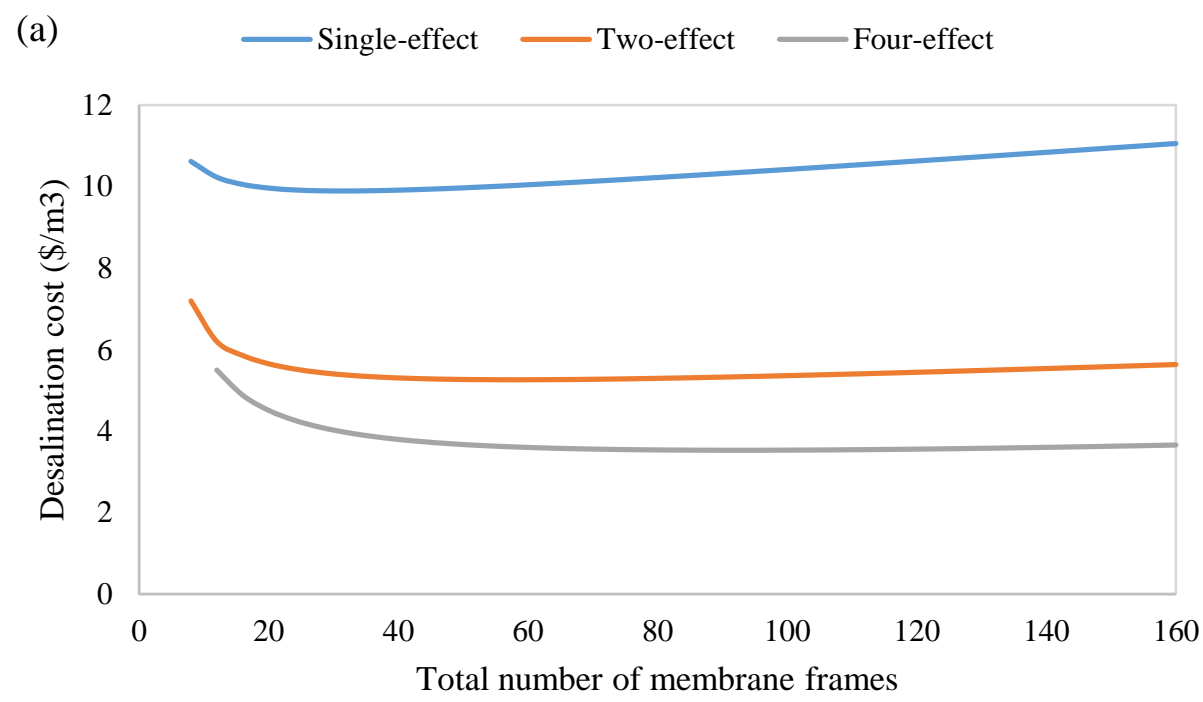

1
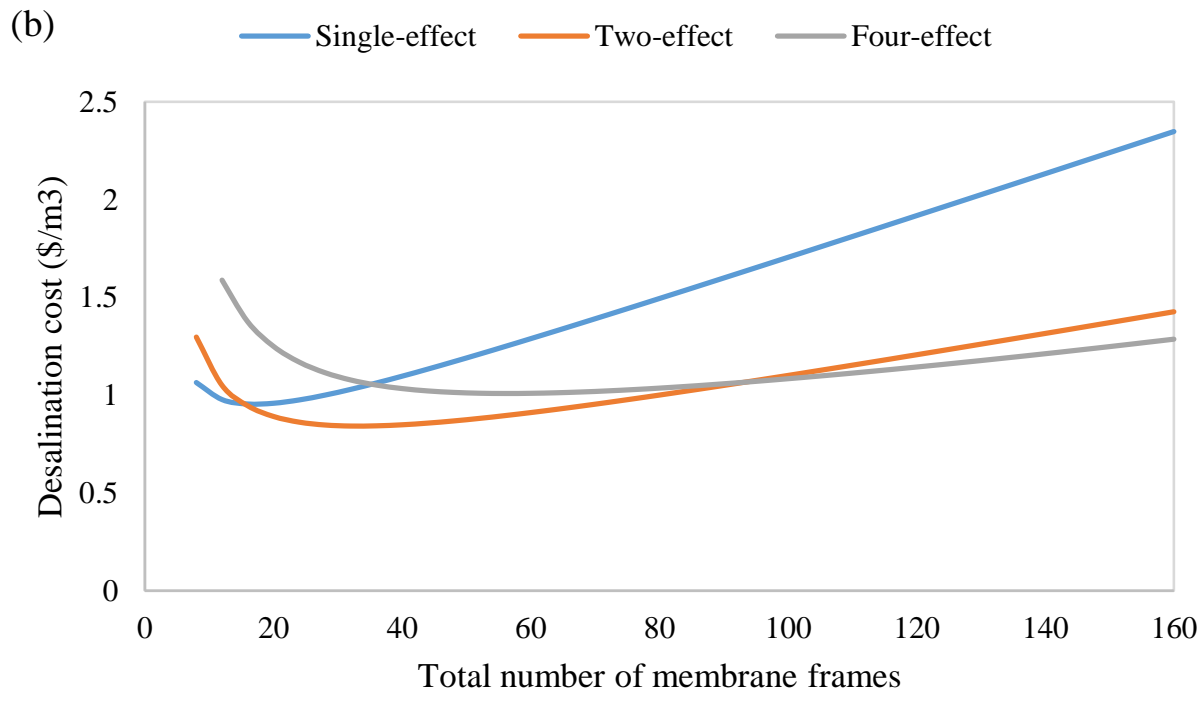

2

3 Figure 12 Desalination cost under different number of membrane frames for (a) high thermal energy cost 4 and (b) free thermal energy with a feed flowrate of 1.5 LPM, a cooling water flowrate of 25 LPM, a hot water temperature of $70^{\circ} \mathrm{C}$ and a cooling water temperature of $25^{\circ} \mathrm{C}$

6 Since the variation of desalination cost with respect to the number of frames is sensitive to the energy cost, 7 the most optimal configuration will also be different under different energy prices. Figure 13(a) summarizes 8 the optimal numbers of membrane frames that minimize the desalination cost. The value is directly 9 correlated to the energy price as well as the number of effects. Under a higher thermal price, more frames 10 should be employed to reduce energy consumption. In addition, a system with more stages will require 11 more frames so that there are sufficient membrane areas in each stage. Figure 13(b) shows the 12 corresponding desalination costs under the optimal configuration, which is also proportional to the energy 13 price. The two-effect configuration is the most cost-effective when the steam price is below $\$ 0.0012 / \mathrm{kWh}$, above which the four-effect system will be more economically competitive. 


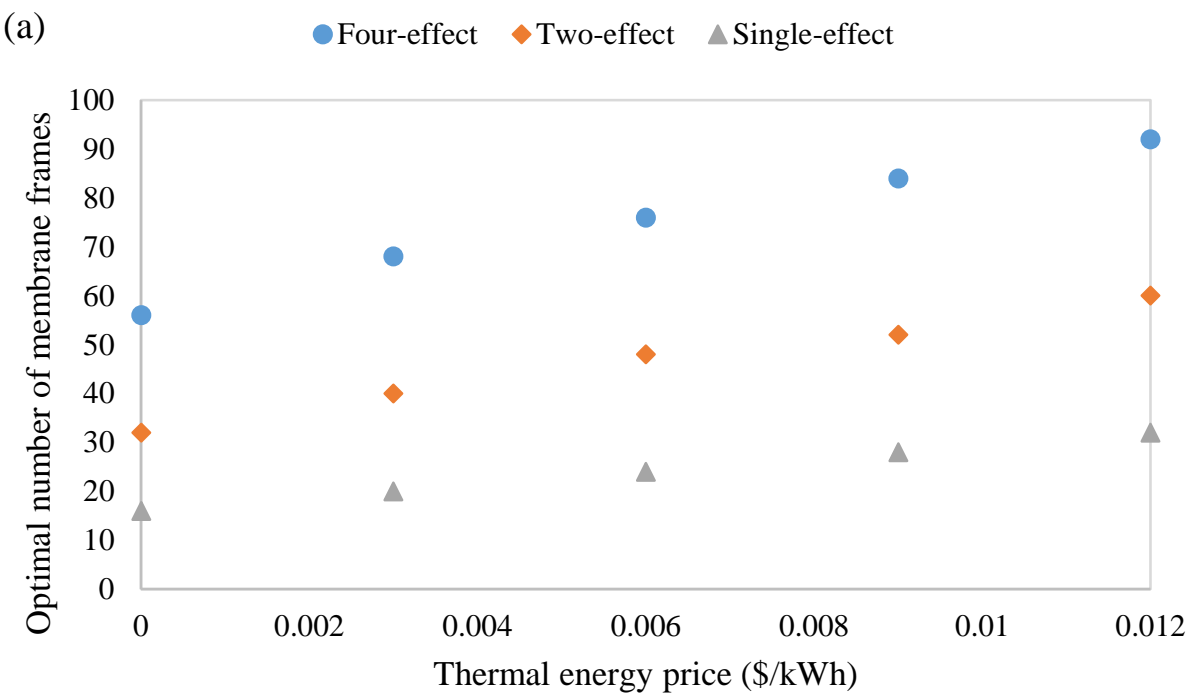

1
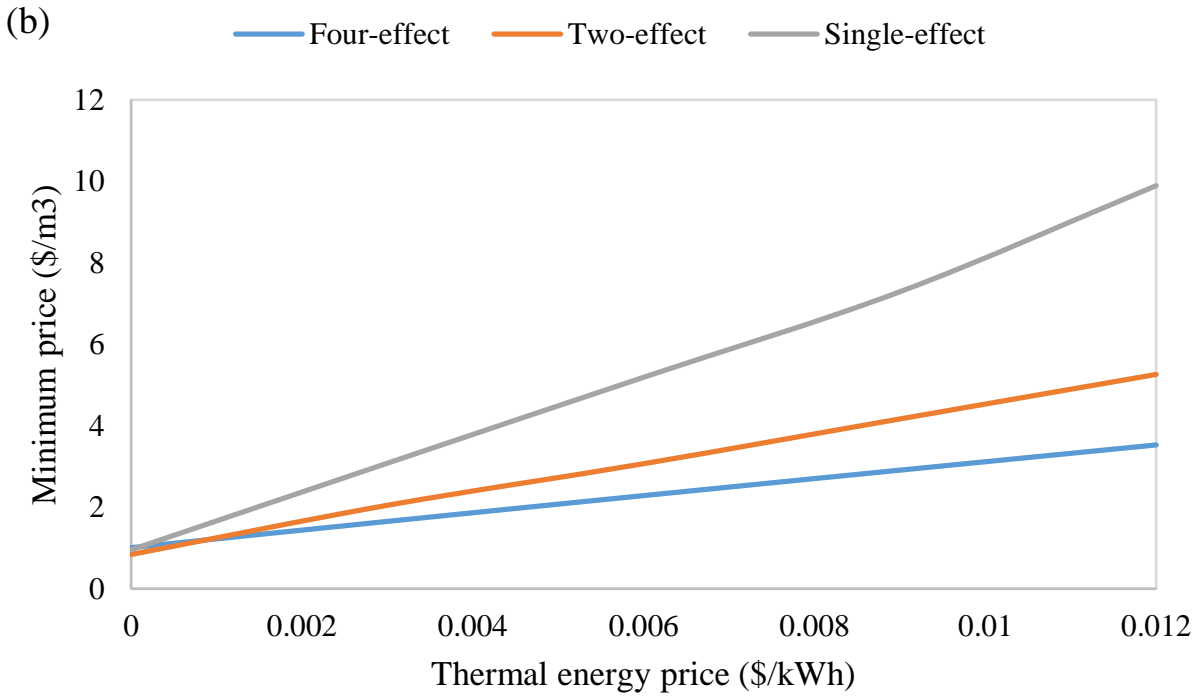

2

3 Figure 13 (a) Optimal number of membrane frames under different steam price and (b) desalination price $4 \quad$ under the optimal configuration with a feed flowrate of 1.5 LPM, a cooling water flowrate of 25 LPM, a hot water temperature of $70^{\circ} \mathrm{C}$ and a cooling water temperature of $25^{\circ} \mathrm{C}$

\section{Conclusions}

8 In this study, a thermo-economic analysis has been conducted for the V-MEMD system to optimize the design and operational parameters and minimize the desalination cost. The system is firstly analyzed thermodynamically to achieve its productivity and energy efficiency, which are observed to be conflicting with each other in most situations. An economic analysis is then conducted to obtain the optimal system parameters under different thermal energy prices. Key results of the current study are summarized as follows: 
(1) The productivity is proportional to the temperature difference between the hot water and the cooling water, and a higher hot water temperature also improves energy efficiency by more than $18 \%$;

(2) Both the productivity and the specific energy consumption will be higher when increasing the flowrates of the seawater and the cooling water. The impact of the feed flowrate is more significant, and it is able to change the productivity and energy efficiency by more than $20 \%$. However, the cooling water flowrate has a marginal effect $(<5 \%)$;

(3) Increasing the number of membrane frames will increase heat and mass transfer, thus boosting freshwater production and reducing energy consumption. However, specific permeate flux for unit membrane area becomes smaller;

(4) Membrane cost and energy cost account for more than $80 \%$ of the final desalination cost, and their relative contributions are subjected to the variation of the energy price;

(5) Under a high thermal energy price, a lower feed flowrate ( $<0.5$ LPM) which leads to lower energy consumption is preferable. The optimal feed flowrate will increase to 0.7 LPM when the thermal energy price is lower than $\$ 0.003 / \mathrm{kWh}$;

(6) There is also an optimal value of the membrane area due to the trade-off between lower energy consumption and a higher membrane cost. The optimal numbers of membrane frames are 32, 60 and 92 for single-effect, two-effect and four-effect configurations, respectively, when the energy price is high at $\$ 0.012 / \mathrm{kWh}$. The values will be smaller when thermal energy with a low cost is available;

(7) The two-effect configuration is more cost-effective due to its higher productivity when the thermal energy price is below $\$ 0.0012 / \mathrm{kWh}$, and the four-effect configuration will dominate when the thermal price gets higher.

The derived results will provide useful information for future design and operation of the V-MEMD system. The final desalination cost not only enables the decision makers to evaluate the economic viability of the system, but also helps the designers to determine the optimal values of several design and operational parameters. However, the results of the economic analysis are based on the adopted economic data, which are not universal. It is expected that the analysis will be adapted to different local conditions to better evaluate the economic viability of the V-MEMD system.

\section{Nomenclature}

A Area of the membrane/foil frame, $\mathrm{m}^{2}$

$C_{h} \quad$ Mass transfer coefficient cross the membrane, $\mathrm{s} / \mathrm{m}$

$c_{p} \quad$ Specific heat, $\mathrm{J} / \mathrm{kg}$

$D \quad$ Distillate flux, $\mathrm{kg} / \mathrm{s} ;$ diffusion coefficient, $\mathrm{m}^{2} / \mathrm{s}$

d Diameter, $\mathrm{m}$

$H \quad$ Enthalpy, $\mathrm{J} / \mathrm{kg}$

$h \quad$ Heat transfer coefficient between the fluid and the frame, $\mathrm{W} / \mathrm{m}^{2}-\mathrm{K}$

$k \quad$ Thermal conductivity of the fluid, W/m-K

$k_{d c} \quad$ Correction factor for heat/mass transfer correlation

$l \quad$ Mesh size of the spacer, $\mathrm{m}$

$m \quad$ Flowrate of the fluid, $\mathrm{kg} / \mathrm{s}$

$M \quad$ Molecular weight, $\mathrm{g} / \mathrm{mol}$

$\mathrm{Nu} \quad$ Nusselt number 


$\begin{array}{ll}p & \text { Pressure, Pa } \\ P r & \text { Prandtl number } \\ Q & \text { Heat input, } \mathrm{J} \\ r & \text { Pore radius, } \mathrm{m} \\ R & \text { Universal gas constant, } \mathrm{J} / \mathrm{mol}-\mathrm{K} \\ R e & \text { Reynolds number in the fluid channels } \\ S c & \text { Schmidt number of the seawater } / \text { hot water } \\ s D & \text { Distillate flux for unit membrane area, } \mathrm{kg} / \mathrm{m}^{2}-\mathrm{s} \\ S E C & \text { Specific energy consumption of the system, } \mathrm{J} / \mathrm{kg} \\ S h & \text { Sherwood number } \\ T & \text { Temperature, }{ }^{\circ} \mathrm{C} \\ u & \text { Cross-sectional velocity of the fluid, } \mathrm{m} / \mathrm{s} \\ X & \text { Salinity of the feed seawater, } \mathrm{kg} / \mathrm{kg}\end{array}$

$\begin{array}{ll}\begin{array}{l}\text { Subscripts } \\ \text { ave }\end{array} & \\ c & \text { Average } \\ c w & \text { Condenser/condensation } \\ \text { eff } & \text { Effect } \\ f & \text { Feed seawater } \\ f g & \text { Latent heat } \\ f i l m & \text { Film } \\ g & \text { Gas phase } \\ h & \text { Hot water } \\ i & \mathrm{i}^{\text {th }} \text { effect } \\ i n & \text { Inlet } \\ m & \text { Membrane; mass transfer } \\ N & \text { Number of effect } \\ o & \text { Outlet } \\ p & \text { Pore } \\ w & \text { Plastic foil wall }\end{array}$

Greek letters

$\mu \quad$ Dynamic viscosity, Pa-s

$\delta \quad$ Thickness of the membrane/film, $m$

$\varepsilon \quad$ Porosity of the membrane; void fraction of the spacer mesh

$\rho \quad$ Density of fluid, $\mathrm{kg} / \mathrm{m}^{3}$

1

$\tau \quad$ Tortuosity of the membrane

\section{Acknowledgement}

3 This research was supported by the Water Desalination and Reuse Center (WDRC), King Abdullah

4 University of Science and Technology (KAUST). 


\section{References}

1. Alkhudhiri, A., N. Darwish, and N. Hilal, Membrane distillation: A comprehensive review. Desalination, 2012. 287: p. 2-18.

2. Alklaibi, A.M. and N. Lior, Membrane-distillation desalination: status and potential. Desalination, 2005. 171(2): p. 111-131.

3. Kim, Y.-D., et al., Performance investigation of a solar-assisted direct contact membrane distillation system. Journal of Membrane Science, 2013. 427: p. 345-364.

4. $\quad$ Abu-Zeid, M.A.E.-R., et al., A comprehensive review of vacuum membrane distillation technique. Desalination, 2015. 356: p. 1-14.

5. Zhang, J., et al., Modelling of vacuum membrane distillation. Journal of membrane science, 2013. 434: p. 1-9.

6. Cerneaux, S., et al., Comparison of various membrane distillation methods for desalination using hydrophobic ceramic membranes. Journal of membrane science, 2009. 337(1-2): p. 55-60.

7. Khayet, M. and T. Matsuura, Membrane distillation: principles and applications. 2011: Elsevier.

8. Banat, F. and N. Jwaied, Economic evaluation of desalination by small-scale autonomous solarpowered membrane distillation units. Desalination, 2008. 220(1-3): p. 566-573.

9. Wang, X., et al., Feasibility research of potable water production via solar-heated hollow fiber membrane distillation system. Desalination, 2009. 247(1-3): p. 403-411.

10. Shim, S., J. Lee, and W.-S. Kim, Performance simulation of a multi-VMD desalination process including the recycle flow. Desalination, 2014. 338: p. 39-48.

11. Summers, E. and J. Lienhard, Cycle performance of multi-stage vacuum membrane distillation (MS-VMD) systems. Proc. 2013 IDA World Congr. Desalin. Water Reuse, Tianjin, China, 2013.

12. Chung, H.W., J. Swaminathan, and D.M. Warsinger, Multistage vacuum membrane distillation (MSVMD) systems for high salinity applications. Journal of Membrane Science, 2016. 497: p. 128141.

13. El-Dessouky, H.T. and H.M. Ettouney, Fundamentals of salt water desalination. 2002: Elsevier.

14. Morin, O., Design and operating comparison of MSF and MED systems. Desalination, 1993. 93(13): p. 69-109.

15. Zhao, K., et al., Experimental study of the memsys vacuum-multi-effect-membrane-distillation ( $V$ MEMD) module. Desalination, 2013. 323: p. 150-160.

16. Heinzl, W. and J. Scharfe, Membrane distillation device. Patent WO, 2010. 2010127819.

17. Naidu, G., et al., Experiments and modeling of a vacuum membrane distillation for high saline water. Journal of Industrial and Engineering Chemistry, 2014. 20(4): p. 2174-2183.

18. Burhan, M., et al., Performance investigation of MEMSYS vacuum membrane distillation system in single effect and multi-effect mode. Sustainable Energy Technologies and Assessments, 2019. 34: p. 9-15.

19. Boutikos, P., et al., A theoretical approach of a vacuum multi-effect membrane distillation system. Desalination, 2017. 422: p. 25-41.

20. Chen, Q., et al., Thermodynamic optimization of a vacuum multi-effect membrane distillation system for liquid desiccant regeneration. Applied energy, 2018. 230: p. 960-973.

21. Ong, C.L., et al., A novel concept of energy reuse from high concentration photovoltaic thermal (HCPVT) system for desalination. Desalination, 2012. 295: p. 70-81.

22. Sharqawy, M.H., J.H. Lienhard, and S.M. Zubair, Thermophysical properties of seawater: a review of existing correlations and data. Desalination and water treatment, 2010. 16(1-3): p. 354-380.

23. Wagner, W. and H.-J. Kretzschmar, IAPWS industrial formulation 1997 for the thermodynamic properties of water and steam. International Steam Tables: Properties of Water and Steam Based on the Industrial Formulation IAPWS-IF97, 2008: p. 7-150. 
24. Martínez-Díez, L., F. Florido-Díaz, and M. Vázquez-González, Study of polarization phenomena in membrane distillation of aqueous salt solutions. Separation Science and Technology, 2000. 35(10): p. 1485-1501.

25. Da Costa, A., A. Fane, and D. Wiley, Spacer characterization and pressure drop modelling in spacer-filled channels for ultrafiltration. Journal of membrane science, 1994. 87(1-2): p. 79-98.

26. Phattaranawik, J., et al., Mass flux enhancement using spacer filled channels in direct contact membrane distillation. Journal of membrane science, 2001. 187(1-2): p. 193-201.

27. Diban, N., et al., Vacuum membrane distillation of the main pear aroma compound: Experimental study and mass transfer modeling. Journal of Membrane Science, 2009. 326(1): p. 64-75.

28. Tavakkoli, S., et al., A techno-economic assessment of membrane distillation for treatment of Marcellus shale produced water. Desalination, 2017. 416: p. 24-34.

29. Ho, W. and K. Sirkar, Membrane handbook. 2012: Springer Science \& Business Media.

30. Sirkar, K.K. and L. Song, Pilot-scale studies for direct contact membrane distillation-based desalination process. 2009: US Department of the Interior, Bureau of Reclamation.

31. Kesieme, U.K., et al., Economic analysis of desalination technologies in the context of carbon pricing, and opportunities for membrane distillation. Desalination, 2013. 323: p. 66-74.

32. Outlook, A.E., Energy information administration. Department of Energy, 2010. 92010(9): p. 115.

33. Helal, A., et al., Optimal design of hybrid RO/MSF desalination plants Part I: Modeling and algorithms. Desalination, 2003. 154(1): p. 43-66. 